\title{
Fiscal Competition, Revenue Sharing and Policy-Induced Agglomeration
}

J. Hindriks, S. Peralta and S. Weber

Discussion Paper 2005-62

\section{Département des Sciences Économiques de l'Université catholique de Louvain}


CORE DISCUSSION PAPER

$2005 / 93$

\title{
FISCAL COMPETITION, REVENUE SHARING, AND POLICY-INDUCED AGGLOMERATION
}

\author{
Jean HINDRIKS ${ }^{1}$, Susana PERALTA ${ }^{2}$ and Shlomo WEBER ${ }^{3}$
}

December 2005

\begin{abstract}
Revenue sharing can be used to discourage low tax regions from competing for capital and firms with high tax regions. However, with heterogeneous regions, revenue sharing involves net transfers across regions and creates a "moral-hazard" problem - that is, regions may want to invest less in market fostering public good when the benefits are shared across nations. This paper analyzes these costs and benefits of revenue sharing. When asymmetric regions compete in capital income taxes only, we show that revenue sharing can be desirable for the high tax region if it is pushed far enough (i.e., J-curve effect), while tax harmonization is always harmful for the low tax region. When regions also compete through public investments, we find that tax competition distorts (downwards) public investments. While revenue sharing discourages public investments due to moral-hazard effect, it remains beneficial in most cases. Moreover, there are new agglomeration forces resulting from public investments, because the inflow of capital raises the incentive for public investments which in turn attract more capital. This leads to the possibility of policy-induced agglomeration (which is different from the classical agglomeration forces in the New Economic geography).
\end{abstract}

JEL Classification: C72, H23, H70.

Keywords: Heterogeneous Regions, Fiscal Federalism, Revenue Sharing, Moral Hazard, Agglomeration.

\footnotetext{
${ }^{1}$ CORE, Université catholique de Louvain.

${ }^{2}$ Faculdade de Economia, Universidade Nova de Lisboa and CORE, Université catholique de Louvain.

${ }^{3}$ CORE, Université catholique de Louvain, SMU and CEPR.
} 


\section{Introduction}

Many federal countries have arranged equalization payments schemes by which a central government transfers resources between jurisdictions. These equalization payments are enshrined in the Canadian constitution (see Smart 1996). Similar schemes are used in Australia, Denmark and Switzerland (see Ahmad and Thomas, 1996) and in many developing countries (see Shah, 2004). They also underlie the European Union's Structural Funds (the Regional Development Fund, the Social Fund, the Financial Instrument for Fisheries Guidance and the European Agricultural Guidance and Guarantees Fund) which amounts to one third of the EU budget between 2000 and 2006 (European Communities, 2004). ${ }^{1}$ Another example is Germany, where in addition to the transfers from the Federal to State governments, there exists a scheme of transfers across states. Payments out of states with more than average revenue per capita into those with less than average amount to 25 million Euros in 1996 (Spahn and Föttinger, 1997). In the US, the state tax sharing is one of two forms of state intergovernmental aid to local governments. The other form consists of appropriated categorical grant-in-aid. Data show that state intergovernmental aid by each state to its local governments (combined city and county) is the largest element of state expenditures. In 2000 the share of state intergovernmental expenditures in state general revenue was on average $33.2 \%$ in the US, and the average for the Southern states was $29.9 \%$. This intergovernmental expenditures includes grant-in-aid, shared taxes and reimbursement for the cost of certain programmes carried out by localities. From 1985 to 2000, payments to local governments have remained at an almost constant percentage of total general expenditures ( $32 \%$ to $35 \%)^{2}$

The alleged purpose of these scheme is an attempt to equalize the citizens access to public services across jurisdictions, i.e., correct fiscal imbalances. Another reason, outlined in a seminal contribution by Boadway and Flatters (1982), ${ }^{3}$ is that fiscal equalization schemes can generate efficiency gains by internalizing the fiscal externality (through federal transfers equal to the

This research was partially supported by the ARC project on Heterogeneity in economics. We gratefully acknowledge helpful comments from Kristian Behrens, Georges Casamatta, Giordano Mion, Pierre Picard, Jacques Thisse and participants of the CORE-IDEI conference on Public Economics (Toulouse, May 2005), the Summer School in the Analysis of Heterogeneity in Social Organizations (CORE, June 2005) and the Workshop on Fiscal Federalism (Barcelona, June 2005)

This text presents research results of the Belgian Program on Interuniversity Poles of Attraction initiated by the Belgian State, Prime Minister's Office, Science Policy Programming. The scientific responsibility is assumed by the authors.

${ }^{1}$ Note that this figure does not include the Common Agricultural Policy.

${ }^{2}$ Fiscal year 2000 data is from the US Bureau of the Census, http://www.census.gov/govs/www/estimate.

${ }^{3}$ See also Stiglitz (1983) and Dahlby and Wilson (1994). 
difference between a jurisdiction's actual source-based revenue and the average level of the federation). While Boadway and Flatters (1982) assumed the lack of jurisdictions' incentives to alter tax rates in response to equalization policies, it has been later shown that the efficiency gains are sustained even if this assumption is relaxed. ${ }^{4}$ Then the federal planner may design intergovernmental transfers to implement the efficient tax rates at the local level. ${ }^{5}$ However, unless there exist lump sum transfers at the federal level, there is no guarantee that all jurisdictions benefit from such transfers and would implement it on a voluntary basis. To address the issue of voluntary inter-regional transfers, Hindriks and Myles (2003) have shown that symmetric jurisdictions, while competing for a mobile tax base, can voluntarily agree to share revenue as a strategic device to limit harmful tax competition. When regions are heterogenous, notably in terms of fiscal revenue, it is no longer clear that they could all benefit from revenue sharing arrangements. Those with low fiscal revenue would benefit while those with high fiscal revenue would bear disproportionate shares of the fiscal burden. This is the first issue we will address in this paper.

The second issue is related to the form of competition between regions. How to attract capital and investments in one jurisdiction? Lighter tax burdens, coupled with public expenditures on infrastructure or other public services that raise fiscal revenue ability, provide a set of policy tools that can influence investment and capital flows. With several policy instruments it is less clear that competitive pressures will lead to a race to the bottom between jurisdictions. For example, while state and local governments in the US vary widely in their public services provision and taxation levels, the competition among these governments has not led to "withering away" taxation and public expenditures. As for Europe, Baldwin and Krugman (2004) have found that tax revenue in percent of GDP differs substantially between the so-called "core" and "periphery" countries. Their explanation is that firms in the core countries are more likely to pay higher taxes in return for better infrastructure and proximity to a larger market. ${ }^{6}$ Using firm level effective tax rates for large Belgian firms, Vandenbussche et al. (2005) find large regional disparities, where the "peripheral" region of Wallonia charges a much lower effective tax rate than the "core" region of Flanders. Head and Mayer (2004) study the choice of location of Japanese firms across Europe and conclude that taxes are far from being the main determinant: the market size and agglomeration externalities play an important role.

\footnotetext{
${ }^{4}$ See, e.g., Bird and Slack (1990), Wildasin (1991), Smart (1998), Koethenbuerger (2002), Bucovetsky and Smart (2004), Figuières et al. (2004).

${ }^{5}$ There is also some empirical literature on the relationship between intergovernmental transfers and local tax effort: Buettner (2005), Dahlby and Warren (2003), Baretti et al. (2003), Hepp and von Hagen (2001), among others. A more theoretical paper is Bordignon et al. (2001) who show how intergovernmental transfers affect tax enforcement.

${ }^{6}$ See also Krogstrup (2003).
} 
In this paper we model tax and public investment competition as follows. We consider an economy with a total stock of capital that is to be divided between two localities. Each locality provides local public investments. As the public investment increases, the productivity of capital is increased and the locality will attract more capital. This assumption implies that fiscal revenue can be written as an increasing function of public investment. There is also a cost to increasing public investments. It is assumed that localities choose their public investments before setting taxes. This simple model shows that flows of capital between localities will induce inefficient choices of taxes and public investments. The reason for this is that the movement of capital between localities reduces the tax base of the locality they leave and increases the tax base they join. These non-market linkages lead to the inefficiency. An important feature of our model is the tax-public investment interaction. In fact, localities that offer a slightly more appealing set of local public investments may appear more attractive even if they tax more capital. If the two issues become entangled in this way then the equilibrium outcome is less clear. Further difficulties with the hypothesis arise when the localities are heterogeneous ex-ante in their capacity to attract capital, as they will in general choose different policies.

We argue that the fiscal externality problem could be resolved together with the issue of fiscal equalization by using revenue sharing, while it cannot with tax harmonization. The method of controlling externalities by internalizing the fiscal externality ensures that private and social costs of taxation become the same. It seems a simple solution but it is not without its difficulties when there are also public investment decisions to be considered. In fact, revenue sharing has two opposite effects in terms of efficiency. The positive effect is to mitigate the harmful tax competition that leads to sub-optimally low tax rates. This positive effect is greater the greater the mobility of the tax base. The negative effect is related to the moral hazard problem: regions exert public investment efforts that enhance tax revenue which are discouraged by revenue sharing insofar as the benefits (in terms of larger tax revenue) are shared across regions. This negative effect is greater the greater the elasticity of public investment to revenue sharing. ${ }^{7}$ Take the extreme case of full revenue sharing. It will clearly eliminate any distortion in tax choices because each locality will internalize the revenue loss it inflicts on other by cutting tax to attract more capital. However this solution will reduce significantly the incentives to invest in local public investments, since all the gains would be shared equally with other localities, while the cost will fall only the locality that raises its public investment. The problem is compounded when localities raises different amounts of tax revenues since

\footnotetext{
${ }^{7}$ Careaga and Weingast (2000) argue that when governments have reelection concerns, revenue sharing due to the common pool effect reduces governments incentive to invest in market fostering public goods, and favors transfers to special interest to gain political support.
} 
then full revenue sharing involves a net transfer from the high revenue to the low revenue localities.

We argue that revenue sharing is desirable under fiscal competition circumstances even if it discourages public investment and if regions are asymmetric. The main challenge is to examine the balance of the two opposite forces. Surprisingly enough, we find that when regions are symmetric, the positive effect always dominates, whatever the mobility of tax base and elasticity of public investment. The reason is that revenue sharing leads the regions to act less agressively.

A further effect of revenue sharing is fiscal equalization: tax sharing is used to absorb fiscal imbalances among regions. Therefore we introduce regional heterogeneity in the model to see if the rich "core" region (with larger tax base) can benefit from sharing its revenue with the poor "periphery" region (with smaller tax base). We study first this issue by assuming away the public investment disincentive from revenue sharing. We then find that if the degree of heterogeneity is low, the fiscal revenue of each region is monotonically increasing with the rate of revenue sharing. However, under high degree of heterogeneity the effect of revenue sharing for the core region is ambiguous. A moderate revenue sharing would result in fiscal revenue loss while a more substantial revenue sharing would result in a gain. This is the so-called J-curve effect of revenue sharing. It arises because, as revenue sharing increases, the tax rates converge redistributing capital to the benefit of the core region.

Adding public investments does not change the result in a fundamental way. However, public investments will be distorted downwards to cope with the fiscal competition. Public investment will also open up the new possibility of capital agglomeration. If capital is sufficiently mobile, one region may attract the entire stock of capital by taking advantage of increasing returns in public infrastructure investment. This policy-induced agglomeration is the result of regional policy choice.

The paper is organized as follows. The next section presents the basic model without public investments and derives the equilibrium outcome. Section 3 proceeds to the analysis of the effect of revenue sharing on the different regions. Section 4 extends the model to account for public investments. Section 5 addresses the issue of agglomeration. Section 6 concludes. The proofs of all propositions are in the Appendix.

\section{The Framework}

Suppose there are two regions, called "core" and "periphery". Both regional governments levy a tax on the mobile tax base (capital). The government in each region has to share the same fraction $\alpha \in[0,1 / 2)$, i.e., ranging from none to full sharing, of its revenue with the other region. We 
assume that the regions correctly anticipate how their tax choices, $t^{c}$ and $t^{p}$, respectively, will affect the allocation of capital. Naturally, the core region has an initial advantage vis-a-vis the periphery in the sense that with identical taxes the core attracts more capital than the periphery. The attractiveness of the core region is explicitly introduced through the heterogeneity parameter $\epsilon$ that measures the relative advantage of the core over the periphery. ${ }^{8}$ It has been shown empirically that capital is not perfectly mobile (Feldstein and Horioka, 1980). We capture this idea by using a Hotelling (linear) location model. The core is located at 0 and the periphery at 1 . The repartition of capital is obtained by equating the (effective) net of tax return adjusted for the mobility cost, $\delta>0$, so that the fraction of capital in the core region, $x^{c}=x^{c}\left(t^{c}, t^{p}\right) \in[0,1]$ solves

$$
(1-t)-\delta\left(x^{c}-\epsilon\right)=\left(1-t^{p}\right)-\delta\left(1-x^{c}\right)
$$

or

$$
x^{c}\left(t^{c}, t^{p}\right)=\frac{1+\epsilon}{2}-\frac{t^{c}-t^{p}}{2 \delta} .
$$

We also define $x^{p}\left(t^{c}, t^{p}\right)=1-x^{c}$. Note that if the taxes in both regions are identical, the fraction of capital attracted is entirely determined by the degree of heterogeneity, i.e., $x^{c}(t, t)=(1+\epsilon) / 2.9$

Given the revenue share $\alpha \in[0,1)$, both regions anticipate the allocation of capital and independently choose their tax rates so as to maximize revenue: ${ }^{10}$

$$
\begin{aligned}
& R^{c}\left(t^{c}, t^{p}\right)=(1-\alpha) t^{c} x^{c}+\alpha t^{p}\left(1-x^{c}\right) \\
& R^{p}\left(t^{c}, t^{p}\right)=(1-\alpha) t^{p}\left(1-x^{c}\right)+\alpha t^{c} x^{c} .
\end{aligned}
$$

It is easy to verify that the revenue functions are concave, thus, yielding the

\footnotetext{
${ }^{8}$ In New Economic Geography models, the core emerges endogenously as the region where the economic activity agglomerates. Here, we define the core as the region with a locational advantage.

${ }^{9}$ It is worth pointing out that the asymmetry between regions makes capital more attracted to one region but does not affect the perceived elasticity of the tax base in the different regions. In most asymmetric fiscal competition models it is the asymmetry in the perceived elasticity of the tax base which is the driving force in generating the asymmetric equilibrium outcome (see Haufler, 2001).

${ }^{10}$ The assumption of revenue maximizing government is a shortcut for describing a situation where residents care sufficiently about the provision of public goods that are financed by tax revenues (see Kanbur and Keen, 1993). What is the appropriate objective function for the principal is ultimately an empirical question. However, it can be argued that if the government maximizes a social welfare function with redistributive objective in mind, then, under revenue constraints, in some cases the optimal policy must be net revenue maximizing. This is true if the welfare gains from higher net revenue are sufficient to offset the losses in welfare due to a net revenue maximizing policy (see Chander and Wilde, 1998). Finally, the focus of our analysis is inter-regional, an not intra-regional, heterogeneity.
} 
Figure 1: Tax Choice

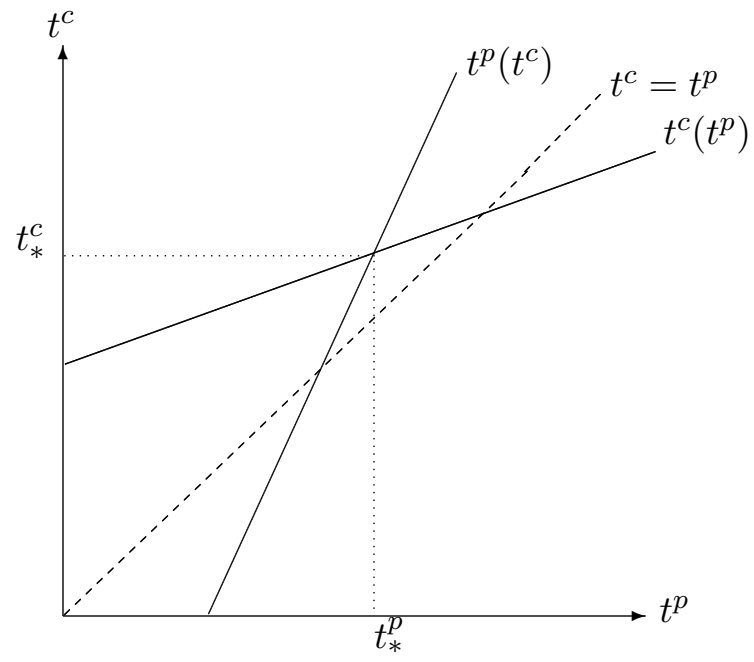

following single-valued tax response functions,

$$
\begin{aligned}
& t^{c}\left(t^{p}\right)=\frac{(1+\epsilon) \delta}{2}+\frac{t^{p}}{2(1-\alpha)} \\
& t^{p}\left(t^{c}\right)=\frac{(1-\epsilon) \delta}{2}+\frac{t^{c}}{2(1-\alpha)}
\end{aligned}
$$

where $0 \leq \alpha<\frac{1}{2}$. Note that taxes are strategic complements, and the effect of revenue sharing is to reinforce this strategic complementarity. Figure 1 depicts the tax response functions. It is immediate to observe that with complete revenue sharing $\alpha=\frac{1}{2}$ the tax competition is fully internalized.

The Nash equilibrium in taxes is

$$
\begin{aligned}
t_{*}^{c} & =\frac{(1-\alpha) \delta}{1-2 \alpha}+\frac{(1-\alpha) \delta \epsilon}{3-2 \alpha} \\
t_{*}^{p} & =\frac{(1-\alpha) \delta}{1-2 \alpha}-\frac{(1-\alpha) \delta \epsilon}{3-2 \alpha} .
\end{aligned}
$$

Thus, the core region taxes more in equilibrium (see Baldwin and Krugman, 2004 and Krogstrup, 2003). The equilibrium allocation of capital $x_{*}^{c}=$ $x^{c}\left(t_{*}^{c}, t_{*}^{p}\right)$ is

$$
x_{*}^{c}=\frac{1+\epsilon}{2}-\frac{\epsilon(1-\alpha)}{3-2 \alpha} .
$$

For $0 \leq \alpha<\frac{1}{2}$ it is easily seen that $x_{*}^{c} \leq 1$ for all $\epsilon \leq 2$, which we assume hereafter. It is worth noting that fiscal competition induces a net loss of capital (relative to fiscal harmonization) for the core region which is taxing more in equilibrium. We have the following result. 
Proposition 2.1 Revenue sharing increases the equilibrium tax in either region and reduces the equilibrium tax gap $t_{*}^{c}-t_{*}^{p}>0$.

Proposition 2.1, together with (1), immediately implies that the share of capital captured by the core region increases in $\alpha$. Indeed, the core region taxes in excess of the periphery and revenue sharing reduces the tax gap redirecting some capital to the core region. Thus, the "pre-sharing" fiscal revenue of the core region, $\pi_{*}^{c}=t_{*}^{c} x_{*}^{c}$ increases with revenue sharing. As we shall see this effect can make revenue sharing beneficial to the core region.

We now proceed to see if both regions can benefit from revenue sharing. We have the following result.

Proposition 2.2 For any degree of mobility and any degree of heterogeneity between regions, the total fiscal revenue increases with revenue sharing whereas the fiscal revenue gap shrinks. Moreover, the fiscal revenue of the periphery increases.

Thus the periphery gains from revenue sharing because the reduction of its tax base is more than offset by the increase of its tax rate and the net transfer from the core region. Obviously, the fact that total fiscal revenue increases with revenue sharing is not a sufficient condition for the core region to gain. We show, however, that if regional heterogeneity, $\epsilon$, is small, then the core region also benefits from revenue sharing. However, if the degree of heterogeneity is high, then modest revenue sharing is harmful to the core region whereas sufficient revenue sharing can become beneficial. The reason is the following. Fiscal revenue in the core region is the sum of its pre-sharing revenue and the net transfer. The first term is increasing with revenue sharing because it raises equilibrium taxes and redirect capital to the core region. When $\epsilon$ is small, then the second term (the net transfer) is small so that the core region also gains from revenue sharing. When $\epsilon$ is large enough, then the net transfer is larger and the core region can lose from revenue sharing. However as revenue sharing increases, the tax rates converge redistributing capital to the benefit of the core region. We summarize our result in the next proposition.

Proposition 2.3 There exists a threshold degree of heterogeneity, $\bar{\epsilon}<2$ such that:

(i) if $\epsilon<\bar{\epsilon}$, the fiscal revenue of the core region always increases with $\alpha$,

(ii) if $\epsilon \geq \bar{\epsilon}$, there is a critical revenue share $\bar{\alpha}(\epsilon)<1 / 2$ such that the fiscal revenue of the core region is first decreasing for $\alpha<\bar{\alpha}(\epsilon)$ and then increasing for $\alpha \geq \bar{\alpha}(\epsilon)$. Moreover, the threshold $\bar{\alpha}(\epsilon)$ is increasing.

Figure 2 depicts the fiscal revenue of the core region as a function of the revenue share for $\epsilon=2 .{ }^{11}$. The graph is a J-curve implying that the

\footnotetext{
${ }^{11}$ The value of $\delta$ is irrelevant since all equilibrium taxes are scaled-up by $\delta$ and is set equal to 1
} 
Figure 2: J-curve

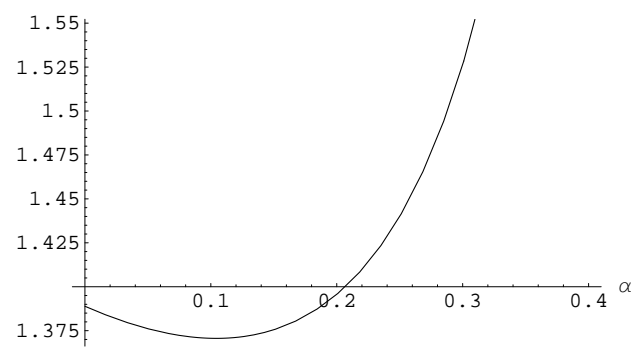

fiscal revenue of the core region rises when revenue sharing is pushed far enough. This result suggests that large revenue sharing could be accepted by rich regions whenever small ones would be resisted. This argument can support the rejection of the gradual revenue share by the Western European countries during the negotiations for their entry to the European Union. Indeed, as our argument shows, a low degree of revenue sharing could be harmful to the core countries.

To summarize, revenue sharing raises the total fiscal revenue and reduces the fiscal gap between regions, implying that the periphery benefits from revenue sharing. This is not so surprising. Perhaps more surprising is the result that the core region can also benefit from revenue sharing, even if its fiscal capacity is much larger, provided that revenue sharing is pushed far enough. In this case the efficiency gain (i.e., relaxing harmful tax competition) from revenue sharing outweighs the cost of transferring resources to the periphery.

The alternative solution to tax competition is the tax harmonization. Could it be beneficial to each region? Consider that tax harmonization takes the following form:

$$
\bar{t}(\lambda)=\lambda t_{*}^{c}+(1-\lambda) t_{*}^{p}
$$

with $0 \leq \lambda \leq 1$. So the uniform tax rate is a convex combination of the equilibrium tax rates. With high $\lambda$ there is harmonization on the highest equilibrium tax and with low $\lambda$ there is harmonization on the smallest tax. We have the following result

Proposition 2.4 Suppose there is no revenue sharing and there is tax harmonization in the form of convex combination between the core and periphery equilibrium taxes. Then there exists no harmonized tax rate that could benefit the periphery.

The reason is that the periphery loses capital as a result of tax harmonization. With harmonization to the bottom, $\lambda \rightarrow 0$, the periphery gets less 
capital but taxes the same as in equilibrium, which lowers its fiscal revenue. Contrarily, with harmonization to the top $\lambda \rightarrow 1$, the core region is better off because it will get more capital, while taxing the same as in equilibrium.

\section{Public Investments}

We now extend the model to account for public investments. Each regional government levies a tax on a mobile tax base (capital) and invests in public inputs which can raise the productivity of capital. Public investment in infrastructures is a long-term decision variable: we capture this feature by modelling a two-stage game, where in the first stage regions choose noncooperatively public investment levels $\left(g^{c}, g^{p}\right)$. The cost of public investment in region $i, I\left(g^{i}\right)$, and the productivity of public investment, $f\left(g^{i}\right)$, are twice continuously differentiable and increasing. We naturally assume that the cost function is convex while the productivity function is concave. The analysis in the previous section is a special case where $f\left(g^{i}\right)=1$ for all $g^{i}$, with $i=c, p$.

Both regions anticipate correctly how their public investment decisions will affect the tax choices $\left(t^{c}, t^{p}\right)$.

Both regions reckon that the repartition of capital varies with public investment and taxes. Let $x^{c}(\mathbf{t}, \mathbf{g}) \in[0,1]$ be the fraction of mobile factor invested in the core region, with $\mathbf{t}=\left(t^{c}, t^{p}\right)$ and $\mathbf{g}=\left(g^{c}, g^{p}\right)$. Again, from the Hotelling (linear) location model, we obtain the capital allocation by equating the net returns, adjusted for locational attachment. That is, $x^{c}=$ $x^{c}(\mathbf{t}, \mathbf{g})$ solves

$$
\left(1-t^{c}\right) f\left(g^{c}\right)-\delta\left(x^{c}-\epsilon\right)=\left(1-t^{p}\right) f\left(g^{p}\right)-\delta\left(1-x^{c}\right),
$$

or

$$
x^{c}=\frac{1+\epsilon}{2}+\frac{\left(1-t^{c}\right) f\left(g^{c}\right)-\left(1-t^{p}\right) f\left(g^{p}\right)}{2 \delta},
$$

where, as before, the parameter $\epsilon>0$ captures the initial regional heterogeneity between core and periphery.

Given the revenue sharing arrangement, regions maximize tax revenue net of the cost of public investments. These expressions are given by:

$$
\begin{aligned}
& R^{c}(\mathbf{t}, \mathbf{g})=(1-\alpha) x^{c} t^{c} f\left(g^{c}\right)+\alpha\left(1-x^{c}\right) t^{p} f\left(g^{p}\right)-I\left(g^{c}\right) \\
& R^{p}(\mathbf{t}, \mathbf{g})=(1-\alpha)\left(1-x^{c}\right) t^{p} f\left(g^{p}\right)+\alpha x^{c} t^{c} f\left(g^{c}\right)-I\left(g^{p}\right) .
\end{aligned}
$$

In this setting, revenue sharing has three different effects. First, it helps to internalize the fiscal externality, thus reducing the negative consequences of fiscal competition. Second, it discourages public investment and, hence, decreases the overall fiscal revenue. Third, it equalizes fiscal revenues. 
We first examine the benchmark efficient policy $\left(t_{o}^{i}, g_{o}^{i}\right)_{i=c, p}$, where a benevolent planner chooses both public investments and taxes in the two regions in order to maximize their joint fiscal revenue. That is,

$$
\left(t_{o}^{i}, g_{o}^{i}\right)_{i=c, p}=\arg \max _{\left(t^{i}, g^{i}\right)} \sum_{i=c, p} x^{i} t^{i} f\left(g^{i}\right)-I\left(g^{i}\right) .
$$

Given that the tax base is inelastic within the federation, it is optimal to set maximal taxes (equal to 1 ). Thus, the share of capital in the core and periphery is $x^{c}=(1+\epsilon) / 2$ and $x^{p}=(1-\epsilon) / 2$, respectively. Therefore, investment in each region equates marginal cost to marginal benefit. Let us denote by $\phi\left(g^{i}\right)$ the ratio of the marginal cost to the marginal benefit of the public investment in region $i$;

$$
\phi\left(g^{i}\right)=\frac{I^{\prime}\left(g^{i}\right)}{f^{\prime}\left(g^{i}\right)} .
$$

We get the following result:

Proposition 3.1 The efficient policy involves higher investments in the core region $g_{o}^{c}>g_{o}^{p}$, with

$$
\phi\left(g_{o}^{c}\right)=\frac{1+\epsilon}{2}>\phi\left(g_{o}^{p}\right)=\frac{1-\epsilon}{2} .
$$

Note that since the function $\phi$ is increasing, the efficient solution yields a larger investment in the core region, $g_{o}^{c}>g_{o}^{p}$.

Using the efficient policy as a benchmark, we now proceed to determine the (subgame perfect) Nash equilibrium in taxes and public investment levels when decisions are devolved to regions. Since public investment creates a negative externality in the other region that is not properly taken into account by the region, one could think that the equilibrium public investment level is too high, leading to overprovision. As we now show, this is not true.

In the second stage of the tax subgame, regions take public investments $\mathbf{g}=\left(g^{c}, g^{p}\right)$ as given and independently choose taxes. The capital allocation resulting from the equilibrium taxes is denoted by $\widetilde{x}(\mathbf{g})$. In Appendix B it is shown that

$$
\widetilde{x}(\mathbf{g})=\frac{1}{2}+\frac{1}{(3-2 \alpha)}\left(\frac{\epsilon}{2}+\frac{f\left(g^{c}\right)-f\left(g^{p}\right)}{2 \delta}\right) .
$$

Comparing (2) and (6), it follows that with no revenue sharing $(\alpha=0)$, the equilibrium tax choices change the perceived elasticity of the tax base to public investments: $\partial \widetilde{x} / \partial g^{c} \neq \partial x^{c} / \partial g^{c}$. Also the perceived elasticity of the tax base to public inputs increases with revenue sharing.

In the first stage of the game, regions choose public investments correctly anticipating the tax equilibrium. The equilibrium investments, taxes and 
capital allocation will be denoted by $\left(\hat{g}^{i}, \hat{t}^{i}, \hat{x}^{i}\right)$ with $i=c, p$. From the first-order conditions for investment choices (see Appendix B), we obtain:

$$
\phi\left(\hat{g}^{c}\right)+\phi\left(\hat{g}^{p}\right)=\frac{2(1-\alpha)^{2}}{3-2 \alpha}<1 .
$$

Since, by Proposition 3.1,

$$
\phi\left(g_{o}^{c}\right)+\phi\left(g_{o}^{p}\right)=1
$$

we can state the following result:

Proposition 3.2 In equilibrium each region under-invests and revenue sharing lowers public investments.

It is noteworthy that there is under-investment even without revenue sharing. The reason is that investment exacerbates the competition in the tax subgame. Indeed, public investments raise the productivity of each unit of capital and lead each region to compete more fiercely in taxes to maintain its capital. Thus higher investments induce lower equilibrium taxes. ${ }^{12}$ Because of the moral-hazard effect, revenue sharing discourages investments.

What about relative equilibrium investments across regions? The following proposition states how the equilibrium public investment levels are related to the distribution of capital and fiscal revenues.

Proposition 3.3 In equilibrium the region with higher public investment also attracts more capital and produces more fiscal revenue.

The fact that when the core region invests more it has more capital is a consequence of optimal tax choices, as clear from (6). For the periphery region, however, to attract more capital it has to invest sufficiently more to offset its initial lack of attractiveness. What the proposition says is that, it will only be worth to invest more for the periphery if this extra investment secures more capital for this region. It is somewhat surprising that in equilibrium the periphery may end up with more capital and fiscal revenue than the core region.

\footnotetext{
${ }^{12}$ More specifically, increasing investment leads the other region to set lower tax rate. Indeed, using (8) in Appendix B, we obtain

$$
\frac{d t^{i}}{d g^{j}}=-\frac{f^{\prime}\left(g^{j}\right)}{\delta}<0, \quad \text { for } \quad i, j=p, c, \quad i \neq j .
$$
}




\section{Impact of revenue sharing}

By Proposition 3.2 revenue sharing discourages public investments in equilibrium. However revenue sharing has also the positive effect of internalizing the fiscal externality. Hence, it is not clear what is the net effect of revenue sharing for either region.

We first point out that with identical regions (i.e. $\epsilon=0$ ) each region benefits from revenue sharing. The reason is that, in the symmetric equilibrium, revenue sharing does not involve redistribution between regions but it leads each region to compete less aggressively by cutting investment and rasing taxes.

Proposition 4.1 With symmetry, each region benefits from revenue sharing regardless of the degree of mobility and the elasticity of public investment to revenue sharing.

Since public investment creates a negative externality in the other region that is not properly taken into account by the region, one could think that the equilibrium public investment level is too high and thus that revenue sharing is desirable because it brings down the public investment level closer to the optimal level. As we have already shown, this is not true. This finding is illustrative of those in the second-best analysis which say that reducing the number of distortions is not necessarily a good thing. Indeed revenue sharing raises fiscal revenue even though it distorts public investment choice. The reason is that revenue sharing also induces improved tax choices. Two small distortions are preferable to a large one.

This symmetric analysis illustrates clearly the efficiency gains of revenue sharing on tax and public investment levels. We now proceed to the analysis of the asymmetric model. The objective is to see if the efficiency gains of revenue sharing can outweigh its cost for the rich region which then has to transfer more to the poor region than it receives.

In order to get a clear insight of the various effects of revenue sharing in the asymmetric game, consider that $f(g)=g$ and $I(g)=g^{2} / 2$. The expressions for equilibrium taxes and public investments are found in Appendix C. We can prove that revenue sharing increases total fiscal revenue. When it comes to regional revenue (and fiscal gap), we use numerical simulations to illustrate the effect of revenue sharing. Figure 3a shows a few illustrative cases when the core region invests more and attracts more capital. Fiscal revenues and fiscal gap are shown here, while taxes, investment levels and equilibrium capital allocation are depicted in Appendix C.

We may draw two main lessons from these numerical simulations. Firstly, it is still possible that both regions benefit from revenue sharing in this setting. Secondly, the interaction of investments, taxes and revenue sharing yields unexpected results. For instance, revenue sharing can exacerbate regional inequalities and harm the poor region (see Figure 3a). Looking at 
Figure 3a: Fiscal revenue and revenue sharing
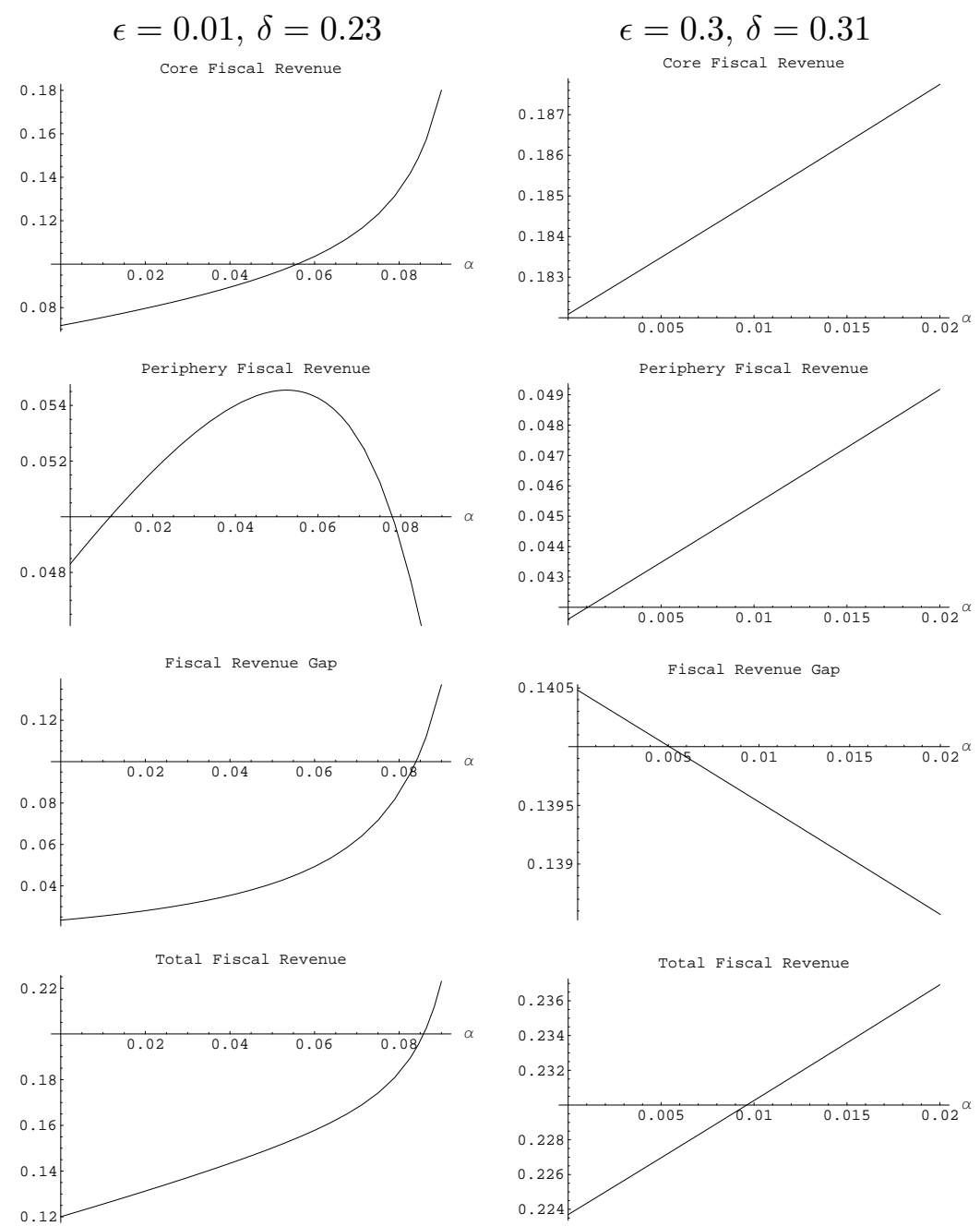

equilibrium taxes and investment levels in Figure 3b (in Appendix C), we may grasp the intuition for this result. As revenue sharing gets higher, the periphery's tax rate becomes very high and its investment very low, as compared to the core region. This causes massive outflow of capital making the periphery worse off.

There exists also the possibility of an equilibrium in which the periphery invests more, attracting more capital and having higher fiscal revenues as a consequence. This catch-up equilibrium is, however, unstable. When such an equilibrium exists, there exist two equilibria with full agglomeration of capital, as we show in the following section. 


\section{$5 \quad$ Policy-induced agglomeration}

One interesting effect of public investment is to bring about new agglomeration forces due to increasing returns in policy choices. Consider a small perturbation from a symmetric allocation of capital; it will induce the region with more capital to slightly invest more and the other region to slightly invest less. This in turn will trigger further reallocation of capital towards the region investing more, increasing further its incentive to invest in public good. A chain reaction is then in place which leads to the progressive agglomeration of capital in a single region through increasing public investments. Indeed, it is then endogenous regional policy choices that cause agglomeration of economic activities in one of the regions. We are dealing here with policy-induced agglomeration, different in nature from the agglomeration arising in the New Economic Geography (NEG) literature, where policy choices play no role. The spatial equilibrium stems from equilibrium behavior of profit maximizing firms, which may profitably locate in one single region, from which they serve foreign markets, when transport costs are sufficiently low. Note that these transportation costs are sometimes taken as a proxy of infrastructure development (e.g. railways or highways that decrease the cost of distance). This is not to be confounded with the public investments in infrastructure we refer to in this paper, which increases capital productivity, not its mobility. ${ }^{13}$

To get more insight on policy-induced agglomeration, we consider identical regions, with no revenue sharing and $f(g)=g, I(g)=g^{2} / 2$. Then the best response functions in public investment are

$$
\begin{aligned}
& g^{c}\left(g^{p}\right)=\frac{3 \delta}{9 \delta-1}-\frac{g^{p}}{9 \delta-1} \\
& g^{p}\left(g^{c}\right)=\frac{3 \delta}{9 \delta-1}-\frac{g^{c}}{9 \delta-1}
\end{aligned}
$$

where, to guarantee concavity of the revenue functions, $\delta \geq \underline{\delta}=1 / 9$.

We can state that (i) public investments are strategic substitutes, and (ii) the slope of the reaction functions is smaller than 1 , if $\delta>2 \underline{\delta}$. Otherwise, the interior equilibrium is unstable. Figure 4 illustrates the best replies in both cases.

We have the following result.

Proposition 5.1 With $\epsilon=0$, for $\underline{\delta}<\delta \leq 2 \underline{\delta}$, there is complete agglomeration of capital in either of the regions. For $2 \underline{\delta}<\delta<3 \underline{\delta}$ there exists a symmetric equilibrium.

Introducing revenue sharing and regional asymmetry still brings about the possibility ofpolicy-induced agglomeration. Again we have that, if the

\footnotetext{
${ }^{13}$ Indeed, the correct analogy is between transport costs in NEG and the mobility cost of capital here for, as will be made clear, agglomeration arises for sufficiently low $\delta$.
} 
Figure 4: Public investment choice
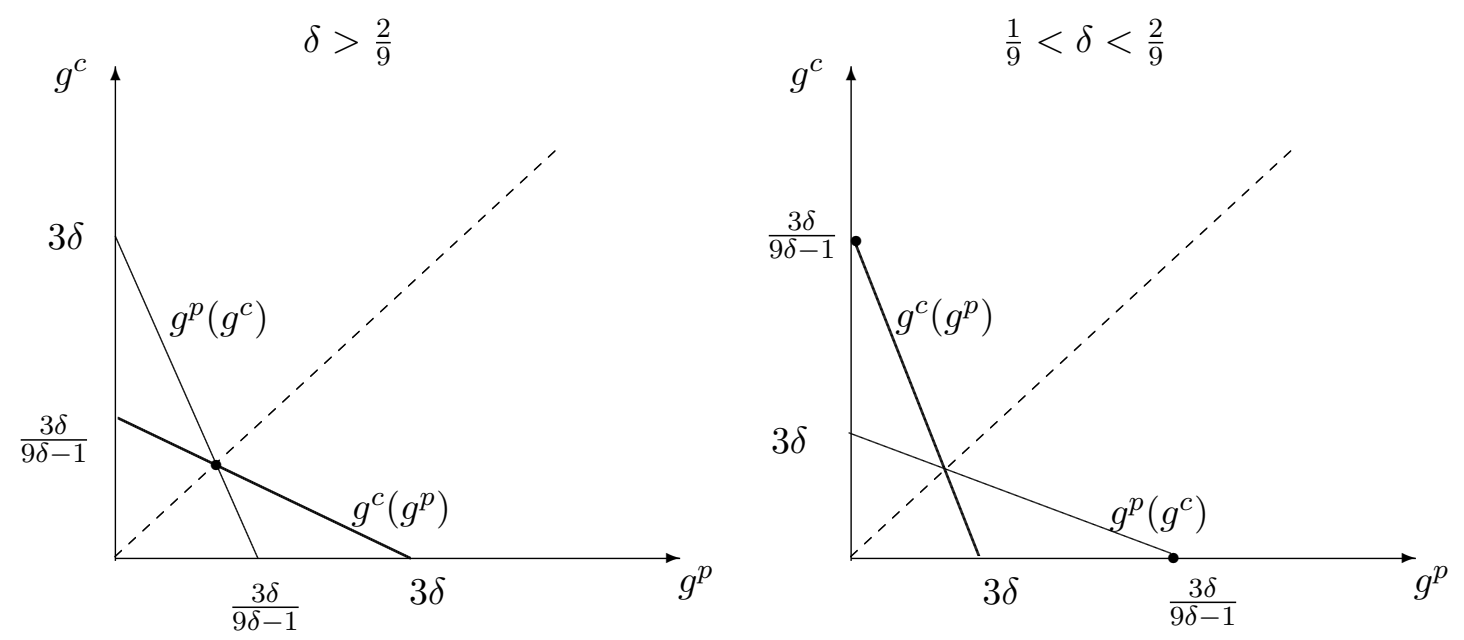

mobility of capital is sufficiently high, the chain reaction with increasing return in public investments leads to full agglomeration.

\section{Conclusion}

This paper tackles the issue of revenue sharing between heterogeneous regions. In our framework, revenue sharing has three effects. Two are efficiency-related (the internalization of the fiscal externality and the discouraging of public investments) and the third one is redistributive. We show that revenue sharing is desirable in a variety of settings, both for the federation as a whole as for each region individually, even for the region which is a net contributor to the system.

Our framework features the interaction between two policy chocies: marketfostering public investments and capital taxation. These are very different in nature. On the one hand, public investments attract capital while taxes drive it away; on the other hand, revenue sharing has a negative impact on public investments and a positive one on taxes. Our main result is that, even in the absence of revenue sharing, there is strategic under-investment in infrastructure. This is because infrastructure raises the stake of tax competition and leads the competing region to set a more competitive (lower) tax. As regards revenue sharing, we show that its positive effect on taxes outweighs the negative one on infrastructures, increasing total fiscal revenue . The reason why revenue sharing can be beneficial for all regions is that it reduces the harmful tax competition among them both in terms of tax and public investments. There are also increasing returns in public investments 
that can cause progressive agglomeration of capital in one region

The statement by the European Economic and Social Committee ${ }^{14}$ is instrumental in reinforcing the policy relevance of the analysis undertaken in this paper:

Western members have expressed fear that the new members may represent too much of a burden for their own economies or the European budget. (...) The public debate now focuses on wage and tax competition, which would be used by new members to attract production facilities and jobs. (...) Companies re-organize (...) in order to benefit both from cost-efficient locations and easy access to expanding markets.

Our results suggest an argument against concerns of "older" EU members' (core countries) related to the budget consequences of the recent EU enlargement. Indeed, the core is shown to benefit from revenue sharing in a variety of settings, in particular if revenue sharing is sufficiently large (the so-called J-Curve effect of revenue sharing). On the other hand, the core countries' should be concerned by the competition in public investments from the periphery regions to attract capital. In a context of increasing globalization, capital mobility is likely to increase and the outcome where the periphery gets to increasingly more capital is a possibility.

\section{Appendices}

\section{Appendix A}

Proof of Proposition 2.1: Let $a=\frac{1}{1-\alpha} \in[1,2]$ for $\alpha \in\left[0, \frac{1}{2}\right]$. The equilibrium tax rates and allocation of capital can be rewritten as

$$
\begin{aligned}
t_{*}^{c} & =\frac{\delta}{2-a}+\frac{\delta \epsilon}{2+a}, \\
t_{*}^{p} & =\frac{\delta}{2-a}-\frac{\delta \epsilon}{2+a} .
\end{aligned}
$$

It is straightforward to verify that both expressions increase in $a$ when $\epsilon<2$, and $t_{*}^{c}-t_{*}^{p}=\frac{2 \delta \epsilon}{2+a}$, is decreasing in $a$.

Proof of Proposition 2.2: Denote by $R_{*}^{c}(\alpha)$ and $R_{*}^{p}(\alpha)$ the revenue at equilibrium for the core and the periphery, respectively. The substitution for the equilibrium taxes and allocation of capital yields the following expression

\footnotetext{
${ }^{14}$ Available online at http://www.esc.eu.int/documents/program_ifri_en.pdf
} 
for $R_{*}^{c}(\alpha)$

$$
\begin{aligned}
& (1-\alpha)\left[\frac{\delta}{2-a}+\frac{\delta \epsilon}{2+a}\right]\left[\frac{1+\epsilon}{2}-\frac{\epsilon}{2+a}\right]+\alpha\left[\frac{\delta}{2-a}-\frac{\delta \epsilon}{2+a}\right]\left[\frac{1-\epsilon}{2}+\frac{\epsilon}{2+a}\right] \\
& =\delta\left[\frac{1}{2(2-a)}+\frac{\epsilon}{a(2-a)}+\frac{a \epsilon^{2}}{2(2+a)^{2}}\right]
\end{aligned}
$$

$R_{*}^{p}(\alpha)$ is obtained by replacing $\epsilon$ by $-\epsilon$, in the above expression. This yields a positive equilibrium revenue gap

$$
R_{*}^{c}(\alpha)-R_{*}^{p}(\alpha)=\frac{2 \delta \epsilon}{a(2+a)}
$$

which is decreasing in $a$. Thus, revenue sharing has equalizing effect on equilibrium regional fiscal revenue levels. The total revenue is given by

$$
R_{*}^{c}(\alpha)+R_{*}^{p}(\alpha)=\delta\left[\frac{1}{(2-a)}+\frac{a \epsilon^{2}}{(2+a)^{2}} \cdot\right]
$$

Therefore, for all $a \in[1,2)$

$$
\frac{\partial R_{*}^{c}(\alpha)+R_{*}^{p}(\alpha)}{\partial a}=\frac{\delta}{(2-a)^{2}}+\frac{(2-a)}{(2+a)^{3}} \delta \epsilon^{2}>0,
$$

implying that the total revenue is increasing in the revenue share.

Proof of Proposition 2.3 We use the following lemma.

Lemma 1 For any degree of mobility there exist a threshold degree of heterogeneity $\bar{\epsilon}(\alpha)$ which is increasing in $\alpha$ with $\bar{\epsilon}(0)=\epsilon_{0}$ and $\lim _{\alpha \rightarrow 1 / 2} \bar{\epsilon}(\alpha)=\infty$ such that $\frac{\partial R_{*}^{c}(\alpha)}{\partial \alpha} \gtreqless 0$ for $\epsilon \lesseqgtr \bar{\epsilon}(\alpha)$.

Proof: Denote

$\frac{d R_{*}^{c}}{d \alpha}=H(\epsilon, a)=\frac{1}{2} a^{2}(2-a)^{-2}-2(1+a)(2+a)^{-2} \epsilon+\frac{1}{2} a^{2}(2-a)(2+a)^{-3} \epsilon^{2}$

We consider solution of the equation $H(\epsilon, a)=0, \widetilde{\epsilon}(a)$ on the rectangle $\Omega=[0, K] \times[1,2-\Delta]$ where $K$ is a sufficiently large number and $\Delta>0$ is sufficiently small.

By the Implicit Function Theorem we obtain

$$
\frac{d \widetilde{\epsilon}}{d a}=-\frac{H_{a}(\widetilde{\epsilon}, a)}{H_{\epsilon}(\widetilde{\epsilon}, a)}
$$


We have

$$
\begin{aligned}
H_{a}(\widetilde{\epsilon}, a)= & \frac{1}{2}\left[2 a(2-a)^{-2}+2 a^{2}(2-a)^{-3}\right]-2\left[(2+a)^{-2}-2(1+a)(2+a)^{-3}\right] \epsilon \\
& +\frac{1}{2}\left[2 a(2-a)(2+a)^{-3}-a^{2}(2+a)^{-3}-3 a^{2}(2-a)(2+a)^{-4}\right] \epsilon^{2} \\
= & 2 a(2-a)^{-3}+2 a(2+a)^{-3} \epsilon-4 a(a-1)(2+a)^{-4} \epsilon^{2} .
\end{aligned}
$$

The last expression is positive at $\epsilon=0$, and has a positive derivative at that point. Moreover, at $\epsilon=2$, it is equal to

$$
\begin{aligned}
H_{a}(2, a) & =2 a\left[(2-a)^{-3}+2(2+a)^{-3}-8(a-1)(2+a)^{-4}\right] \\
& =2 a(2-a)^{-3}+12 a(2-a)(2+a)^{-4}>0
\end{aligned}
$$

with $H_{a}(2, a) \rightarrow \infty$ as $a \rightarrow 2$. Furthermore,

$$
H_{\epsilon}(\widetilde{\epsilon}, a)=-2(1+a)(2+a)^{-2}+a^{2}(2-a)(2+a)^{-3} \epsilon .
$$

This expression is increasing in $\epsilon$ with $H_{\epsilon}(0, a)<0$. At $\epsilon=2$ it is equal to

$$
\begin{aligned}
H_{\epsilon}(2, a) & =-2(1+a)(2+a)^{-2}+2 a^{2}(2-a)(2+a)^{-3} \\
& =-2(2+a)^{-3}\left[2+3 a+(a-1) a^{2}\right]<0,
\end{aligned}
$$

Thus, the derivative $d \widetilde{\epsilon} / d a$ is positive on the rectangle $\Omega=[0,2-\Delta] \times[1,2-$ $\Delta]$. Since at $a=1, \widetilde{\epsilon}<1$ and $\lim _{a \rightarrow 2} \widetilde{\epsilon}(a)=\infty$, we complete the proof of the lemma.

By using Lemma 1 and inverting the increasing function $\bar{\epsilon}(\alpha)$, we obtain the increasing function $\bar{\alpha}(\epsilon)=\bar{\epsilon}^{-1}(\alpha)$, which completes the proof of the proposition.

\section{Proof of Proposition 2.4:}

Using equilibrium taxes, the harmonized tax is

$$
\bar{t}(\lambda)=\delta\left[1+\frac{\epsilon}{3}(2 \lambda-1)\right]
$$

This gives the revenue in the periphery

$$
\bar{R}^{p}(\lambda)=\delta \bar{t}(\lambda) \frac{1-\epsilon}{2}
$$

The revenue in the periphery attains a maximum at $\lambda=1$. So

$$
\bar{R}^{p}(1)=\delta\left(1+\frac{\epsilon}{3}\right)\left(\frac{1-\epsilon}{2}\right)
$$

Compared to the equilibrium revenue without harmonization

$$
R^{p}=\delta\left(1-\frac{\epsilon}{3}\right)\left(\frac{1}{2}-\frac{\epsilon}{6}\right)
$$


It follows that

$$
R^{p}>\bar{R}^{p}(\lambda) \text { for all } \lambda
$$

which completes the proof.

Proof of Proposition 3.1: Given that the total stock of capital is fixed, maximizing total revenue requires $t^{c}=t^{p}=1$.

Given optimal taxes, $x^{c}=\frac{1+\epsilon}{2}$, and the optimal public investment levels satisfy

$$
\phi\left(g_{o}^{c}\right)=\frac{1+\epsilon}{2} \text { and } \phi\left(g_{o}^{p}\right)=\frac{1-\epsilon}{2} .
$$

The optimal levels involve more investment in the core region $g_{o}^{c}>g_{o}^{p}$. Furthermore, those levels satisfy $\phi\left(g_{o}^{c}\right)+\phi\left(g_{o}^{p}\right)=1$.

\section{Appendix B: Solving the public investments - tax game}

- Part 1. First order conditions of the tax subgame

The first order conditions are

$$
\begin{gathered}
\frac{R^{c}}{\partial t^{c}}=(1-\alpha) x^{c} f\left(g^{c}\right)+\left[\alpha t^{p} f\left(g^{p}\right)-(1-\alpha) t^{c} f\left(g^{c}\right)\right] \frac{f\left(g^{c}\right)}{2 \delta}, \\
\frac{\partial R^{p}}{\partial t^{p}}=(1-\alpha)\left(1-x^{c}\right) f\left(g^{p}\right)+\left[\alpha t^{c} f\left(g^{c}\right)-(1-\alpha) t^{p} f\left(g^{p}\right)\right] \frac{f\left(g^{p}\right)}{2 \delta},
\end{gathered}
$$

which are equivalent to

$$
\begin{aligned}
& (2-a) \frac{t^{c} f\left(g^{c}\right)}{2 \delta}=\alpha+(1-2 \alpha) x^{c} \\
& (2-a) \frac{t^{p} f\left(g^{p}\right)}{2 \delta}=\alpha+(1-2 \alpha)\left(1-x^{c}\right) .
\end{aligned}
$$

By solving, we get

$$
\begin{aligned}
t^{c} & =\left(3+\epsilon+\frac{f\left(g^{c}\right)-f\left(g^{p}\right)}{\delta}\right) \frac{1}{3 f\left(g^{c}\right)} \\
t^{p} & =\left(3-\epsilon+\frac{f\left(g^{p}\right)-f\left(g^{c}\right)}{\delta}\right) \frac{1}{3 f\left(g^{p}\right)} .
\end{aligned}
$$

- Part 2. First order conditions of the investment subgame

By using (7) and straightforward algebra, we obtain

$$
\begin{aligned}
R^{c} & =\frac{2 \delta}{a}\left(\frac{\alpha}{2-a}+\widetilde{x}(\widetilde{x}-\alpha)\right)-I\left(g^{c}\right), \\
R^{p} & =\frac{2 \delta}{a}\left(\frac{\alpha}{2-a}+(1-\widetilde{x})(1-\widetilde{x}-\alpha)\right)-I\left(g^{p}\right) .
\end{aligned}
$$


The Nash equilibrium in investment solves the first order conditions:

$$
\begin{aligned}
\frac{\partial R^{c}}{\partial g^{c}} & =\frac{(2 \widetilde{x}-\alpha) f^{\prime}\left(g^{c}\right)}{2+a}-I^{\prime}\left(g^{c}\right)=0, \\
\frac{\partial R^{p}}{\partial g^{p}} & =\frac{(2(1-\widetilde{x})-\alpha) f^{\prime}\left(g^{p}\right)}{2+a}-I^{\prime}\left(g^{p}\right)=0 .
\end{aligned}
$$

which can be rewritten as:

$$
\begin{aligned}
\frac{2 \widetilde{x}-\alpha}{2+a} & =\phi\left(g^{c}\right) \\
\frac{2(1-\widetilde{x})-\alpha}{2+a} & =\phi\left(g^{p}\right) .
\end{aligned}
$$

Note that

$$
\frac{d^{2} R^{c}}{d\left(g^{c}\right)^{2}}=\frac{f^{\prime \prime}\left(g^{c}\right)(2 \tilde{x}-\alpha)}{2+a}+\frac{a\left(f^{\prime}\left(g^{c}\right)\right)^{2}}{\delta(2+a)^{2}}-I^{\prime \prime}\left(g^{c}\right),
$$

which, when the first order condition is satisfied, can be stated as

$$
f^{\prime \prime}\left(g^{c}\right) \phi\left(g^{c}\right)+\frac{a}{\delta(2+a)^{2}}\left(f^{\prime}\left(g^{c}\right)\right)^{2}-I^{\prime \prime}\left(g^{c}\right) .
$$

Then the sufficient conditions for quasi-concavity of the payoff function (hence, existence of an equilibrium in investment levels) are: (i) the value in (14) is non-positive; (ii) the value of (11) is nonnegative when $g^{c}=0$, and (iii) the expression in (11) is continuous in $g^{c}$.

Proof of Proposition 3.3: First let us rule out the possibility $g^{c}=g^{p}$. Indeed, from (6), if $g^{c}=g^{p}$, the capital allocation is $\hat{x}=\frac{1}{2}+\frac{a \epsilon}{2(2+a)}>\frac{1}{2}$, which, by (12), implies that $g^{c}>g^{p}$, a contradiction.

Taking the ratio of the two expressions in (12), we have

$$
\frac{2 \tilde{x}-\alpha}{2(1-\tilde{x})-\alpha}=\frac{\phi\left(g^{c}\right)}{\phi\left(g^{p}\right)},
$$

implying that $\phi\left(g^{c}\right)>\phi\left(g^{p}\right)$ if and only if $\tilde{x}>1 / 2$. Finally, multiplying both sides of (7) by $\tilde{x}$ and $1-\tilde{x}$, respectively, and taking the ratio, we have

$$
\frac{t^{c} f\left(g^{c}\right) x^{c}}{t^{p} f\left(g^{p}\right)\left(1-x^{c}\right)}=\frac{x^{c}\left(\alpha+(1-2 \alpha) x^{c}\right)}{1-x^{c}\left(\alpha+(1-2 \alpha)\left(1-x^{c}\right)\right)} .
$$

Since the value $x^{c}\left(\alpha+(1-2 \alpha) x^{c}\right)$ is increasing in $x^{c}$, we conclude that the region with a higher fiscal revenue also gets more capital.

Proof of Proposition 4.1 In the symmetric case where $\epsilon=0$, there is a symmetric outcome in taxes and public investments. The first order 
conditions for taxes (7) and public investments (12), evaluated at $t=t^{p}, g=$ $g^{p}, \bar{x}=\widetilde{x}=1 / 2$ yield:

$$
t f(g)=\frac{\delta}{2-a} \text { and } \phi(g)=\frac{1}{a(2+a)} .
$$

Since $\phi$ is increasing, the last expression guarantees that $g$ is a decreasing function of $a$, and, as expected, revenue sharing reduces the equilibrium public investment level in each region. Also, note that, due to fiscal internalization, equilibrium taxes are increasing with revenue sharing:

$$
\frac{d t}{d a}=\delta\left[\frac{f(g)-(2-a) f^{\prime}(g) \frac{d g}{d a}}{f(g)^{2}(2-a)^{2}}\right]>0 .
$$

We now show that revenue sharing is desirable for both regions regardless of the elasticity of public investment to revenue sharing (i.e for all $\phi>0$ ) and the degree of mobility (i.e., for all $\delta>0$ ). At the symmetric Nash equilibrium, tax sharing cancels out and regional payoff is

$$
R(a)=\frac{t f(g)}{2}-I(g)=\frac{\delta}{2(2-a)}-I(g) .
$$

The result now follows by differentiating this expression with respect to $a$ :

$$
\frac{\partial R(a)}{\partial a}=\frac{\delta}{2(2-a)^{2}}-I^{\prime}(g) \frac{d g}{d a}=\frac{\delta}{2(2-a)^{2}}+\frac{a I^{\prime}(g)}{\phi^{\prime}}>0
$$

for all values of mobility and elasticity $\delta, \phi>0$.

\section{Appendix C: Simulations in Section 4}

First note that from (13) we have

$$
\frac{\partial^{2} R^{c}}{\partial\left(g^{c}\right)^{2}}=\frac{1-\alpha}{\delta(3-2 \alpha)^{2}}-1
$$

which is negative for $\delta>\underline{\delta}(\alpha)=\frac{1-\alpha}{(3-2 \alpha)^{2}}=\frac{1}{a(2+a)}$. Thus, the revenue functions are globally concave if the value of $\delta$ is bounded away from $\underline{\delta}(\alpha)$.

Given revenue sharing, the interior equilibrium outcome is given by

$$
\begin{aligned}
\hat{t}^{c} & =\delta a \frac{2+a}{2-a} \frac{\delta(2+a)(2+a+(2-a) \epsilon)-2 a}{\delta(2+a)\left(2+a+a^{2} \epsilon\right)-2 a}, \\
\hat{t}^{p} & =\delta a \frac{2+a}{2-a} \frac{\delta(2+a)(2+a-(2-a) \epsilon)-2 a}{\delta(2+a)\left(2+a-a^{2} \epsilon\right)-2 a} \\
\hat{x}^{c} & =\frac{1}{2}+\frac{1}{2} \frac{(2+a) \delta \epsilon a}{(2+a)^{2} \delta-2 a}, \\
\widehat{g}^{c} & =\frac{1}{a(2+a)}+\frac{a \delta \epsilon}{(2+a)^{2} \delta-2 a}, \\
\widehat{g}^{p} & =\frac{1}{a(2+a)}-\frac{a \delta \epsilon}{(2+a)^{2} \delta-2 a} .
\end{aligned}
$$


Plugging the equilibrium values in the payoff functions, we get

$$
\begin{aligned}
R^{c}(a) & =\frac{1}{2}\left(\frac{\delta}{2-a}-\frac{1}{a^{2}(2+a)^{2}}\right)-\frac{a \delta^{2}}{2} \frac{a-(2+a)^{2} \delta}{\left((2+a)^{2} \delta-2 a\right)^{2}} \epsilon^{2} \\
& +\frac{\delta}{a(2+a)} \frac{(2+a)^{2} \delta-a}{(2+a)^{2} \delta-2 a} \epsilon, \\
R^{c}(a) & =\frac{1}{2}\left(\frac{\delta}{2-a}-\frac{1}{a^{2}(2+a)^{2}}\right)-\frac{a \delta^{2}}{2} \frac{a-(2+a)^{2} \delta}{\left((2+a)^{2} \delta-2 a\right)^{2}} \epsilon^{2} \\
& -\frac{\delta}{a(2+a)} \frac{(2+a)^{2} \delta-a}{(2+a)^{2} \delta-2 a} \epsilon
\end{aligned}
$$

Total fiscal revenue is

$$
R^{c}(a)+R^{p}(a)=\frac{\delta}{2-a}-\frac{1}{a^{2}(2+a)^{2}}-a \delta^{2} \frac{a-(2+a)^{2} \delta}{\left((2+a)^{2} \delta-2 a\right)^{2}} \epsilon^{2} .
$$

and the gap is

$$
R^{c}(a)-R^{p}(a)=\frac{2 \delta}{a(2+a)} \frac{(2+a)^{2} \delta-a}{(2+a)^{2} \delta-2 a} \epsilon .
$$

It is straightforward to show that $R^{c}(a)+R^{p}(a)$ is increasing in $a$ at the stable interior equilibrium, i.e., when $(2+a)^{2} \delta-2 a>0$.

Figure $3 \mathrm{~b}$ displays equilibrium taxes, investment levels and capital allocation for the examples presented in section 4. The dashed (solid) curves refer to the periphery (core). 
Figure 3b: Equilibrium taxes, investment levels and capital allocation

$$
\epsilon=0.01, \delta=0.23
$$
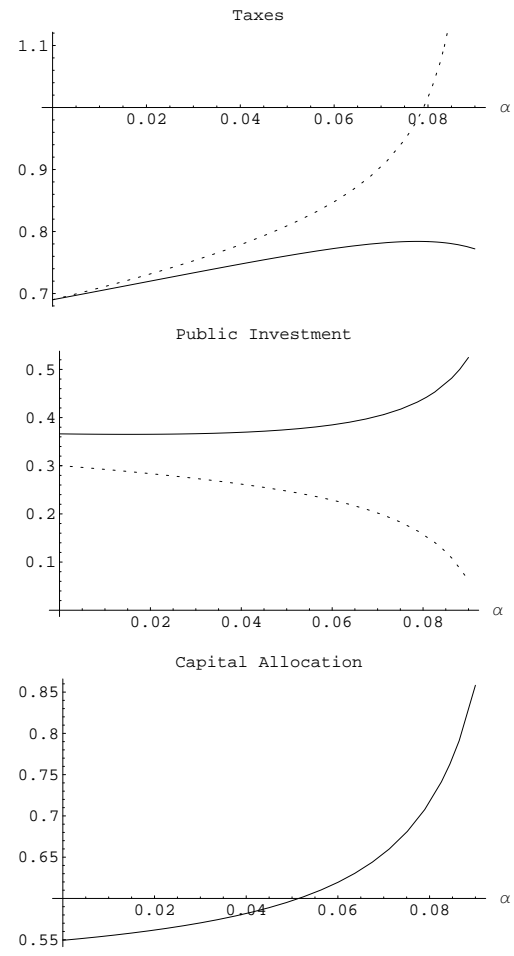

$\epsilon=0.3, \delta=0.31$

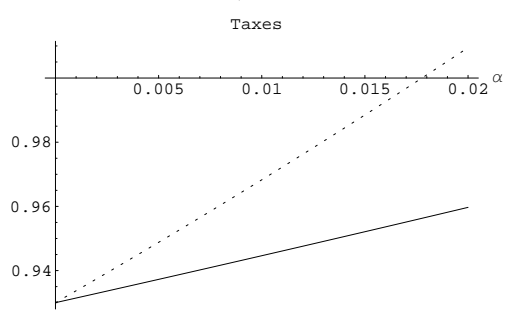

Public Investment
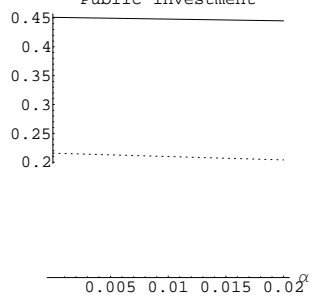

Capital Allocation

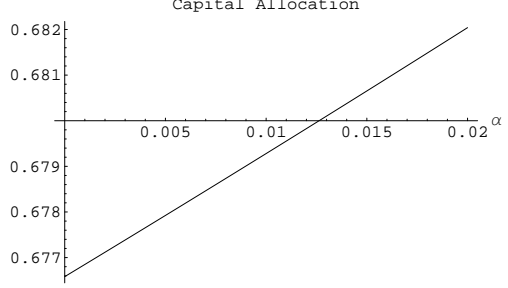

\section{References}

[1] Ahmad, E. and R. Thomas, 1996, Types of Transfers: a General Formulation, in Financing Decentralized Expenditures: An International Comparison of Grants, E. Ahmad, ed., Aldershot UK: Eward Elgar.

[2] Baretti, C., B. Huber and K. Lichtblau, 2002, A Tax on Tax Revenue: the Incentive Effects of Equalizing Transfers: Evidence from Germany, International Tax Journal 9, 631-649.

[3] Baldwin R. and P. Krugman, 2004, Agglomeration, Integration and Tax Harmonization, European Economic Review 48(1), 1-23.

[4] Bird, R. and E. Slack, 1990, Equalization: The Representative Tax System Revisited, Canadian Tax Journal 38, 913-27.

[5] Boadway, R. and F. Flatters, 1982, Efficiency and Equalization Payments in a Federal System of Government: A Synthesis and Extension of Recent Results, Canadian Journal of Economics 15, 613-33. 
[6] Bordignon, M., P. Manasse and G. Tabellini, 2001, Optimal Regional Redistribution under Asymmetric Information, American Economic Review, vol. 91(3), 709-723.

[7] Bucovetsky, S. and M. Smart, 2004. The efficiency consequences of local revenue equalization: tax competition and tax distortions, Journal of Public Economic Theory, forthcoming.

[8] Buettner, 2005, The Incentive Effect of Fiscal Equalization Transfers on Tax Policy, Journal of Public Economics, forthcoming.

[9] Careaga, M., and B. R. Weingast, 2000, The Fiscal Pact with the Devil: A Positive Approach to Fiscal Federalism, Revenue Sharing, And Good Governance, Working Paper, Hoover Institution, Stanford University.

[10] Chander, P. and L. Wilde, 1998, A General Characterization of Optimal Income Tax Enforcement, Review of Economic Studies 65(1), 165-83.

[11] Dahlby, B. and L. Wilson, 1994, Fiscal Capacity, Tax Effort and Optimal Equalization Grants, Canadian Journal of Economics 27, 657-72.

[12] Dahlby, B. and N. Warren, 2003, The Fiscal Incentive Effects of the Australian Equalization System, Economic Recors 79, 434-445.

[13] European Communities, 2004, Working for the Regions. Luxembourg.

[14] Feldstein, M. and C. Horioka, 1980, Domestic Saving and International Capital Flows, The Economic Journal 90(358), 314-329.

[15] Figuières, C., J. Hindriks and G. Myles, 2004, Revenue Sharing versus Expenditure Sharing, International Tax and Public Finance 11, 155-74.

[16] Haufler, A., 2001, Taxation in Global Economy, (Cambridge University Press).

[17] Head, K. and T. Mayer, 2004, Market potential and the location of Japanese investment in the European Union, The Review of Economics and Statistics 86(4), 959-972.

[18] Hindriks, J., and G.D.Myles, 2003, Strategic Inter-regional Transfers, Journal of Public Economic Theory5, 229-48.

[19] Kanbur, R. and M. Keen, 1993, Jeux Sans Frontieres: Tax Competition and Tax Coordination When Countries Differ in Size, American Economic Review 83, 877-92.

[20] Koethenbuerger, M, 2002, Tax Competition and Fiscal Equalization, International Tax Journal 9, 391-408. 
[21] Krogstrup, S., 2003, Are capital taxes running to the bottom in the EU?, HEI Working Paper 01/2003.

[22] Shah, A., 2004, Fiscal Decentralization in Developing and Transition Economies: Progress, Problems, and the Promise, Policy Research Working Paper Series 3282, The World Bank.

[23] Smart, M.,1998, Taxation and Deadweight Loss in a System of Intergovernmental Transfers, Canadian Journal of Economics, vol. 31(1), $189-206$.

[24] Spahn, Paul B., and Wolfgang Föttinger, 1997, Germany in Teresa TerMinassian, ed. Fiscal Federalism in Theory and Practice, Washington, D.C.: International Monetary Fund.

[25] Stiglitz, J., 1983, The Theory of Local Public Goods Twenty-Five Years After Tiebout: a Perspective, in Local Provision of Public Services: The Tiebout Model after Twenty-Five Years, G. R. Zodrow (ed.), New York: Academic Press, 17-53.

[26] Vandenbussche, H. B. Janssen and K. Crabbé, 2005, Is there Regional Tax Competition in Belgium? De Economist-Netherlands.

[27] Hepp, R. and J. von Hagen, 2001, Regional Risksharing and Redistribution in the German Federation, CEPR Discussion Papers 2662

[28] Wildasin, D., 1991, Income Redistribution in a Common Labor Market, American Economic Review, vol. 81(4), pages 757-74. 
Département des Sciences Économiques de l'Université catholique de Louvain

Institut de Recherches Économiques et Sociales

Place Montesquieu, 3

1348 Louvain-la-Neuve, Belgique 